\title{
Role of information and communication technologies (ICTs) in behavior change communication in northern India
}

Population Council

Follow this and additional works at: https://knowledgecommons.popcouncil.org/departments_sbsr-rh

Part of the International Public Health Commons, Science and Technology Policy Commons, and the Telemedicine Commons

How does access to this work benefit you? Let us know!

\section{Recommended Citation}

"Role of information and communication technologies (ICTs) in behavior change communication in northern India," Shaping Demand and Practices to Improve Family Health Outcomes in Northern India Policy Brief. New Delhi: Population Council, 2010. 


\section{Role of information and communication technologies (ICTs) in behavior change communication in northern India}

\section{Background}

Since the late 1990s countries in Asia, Africa and Latin America have been witnessing a phenomenal growth in the use of new information and communication technologies (ICTs), in particular mobile phones and the internet (Figure 1) ${ }^{1}$.

Figure 1: Global trends in use of ICT, 1998-2008

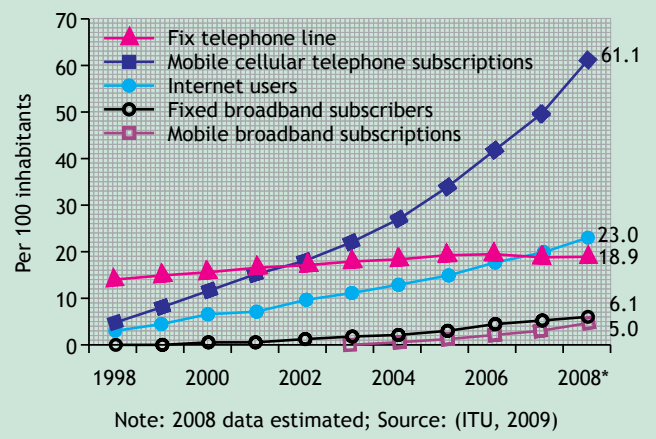

India too has been witnessing these trends. In November 2009 the telephone subscriber base in India was 543 million landline and mobile subscribers, and the overall telephone density was 46 percent $^{2}$.

The growth in penetration and use of ICTs presents unprecedented opportunities to communicate with rural audiences, and may soon be the largest media opportunity in rural India. For example, the Indian Readership Survey (IRS) reports the reach of TV and radio to be 28 percent and 30 percent respectively, among married men aged 18-34 years in 2008 . In contrast, ownership of mobile phones reached 14 percent - more than half the reach of TV - and has been growing at 50 percent annually. At this rate of growth, ownership of mobile phones will surpass the reach of TV and radio by 2010 .

${ }^{1}$ International Telecommunications Union. 2009. Measuring the information society <http://www.itu.int/ITUD/ict/publications/idi/2009/material/IDI2009_w5.pdf> ${ }_{2}$ TRAI. 2010. Information note to the press (press release no. 79 /2009): Telecom subscription data as on 30 November 2009 $<$ http://www.trai.gov.in/WriteReadData/trai/upload/PressRel eases/712/pr23dec09no79.pdf >

${ }^{3}$ DIT. 2009. CSC Implementation Status across India as on 30 November 2009

$<$ http://www.mit.gov.in/download/CSC301109.pdf >
Similarly, the reach of the internet in India is likely to grow exponentially between 2010 and 2015 primarily as a result of efforts of the Government of India (GoI). As part of the GoI's National e-Governance Plan (NeGP), 57,599 rural internet kiosks (common service centers; CSCs) were established by November 2009 in India ${ }^{3}$.

In the context of the growth of new ICTs, in 2010 Abt Associates, a partner in the Population Council-led consortium conducted a study to assess (a) the status of ICT use in the health sector; (b) the existing and emerging ICT applications that have the potential to rapidly accelerate the adoption of family health practices; and (c) use of emerging technologies in a behavior change communication (BCC) strategy and the delivery of services for improving family health outcomes.

The study was funded by the Population Council as a subcontract to Abt Associates Inc, from an award granted by the Bill and Melinda Gates Foundation.

\section{Methodology}

The proliferation of new ICTs has stimulated interest in developing and testing applications of these media in health and development-particularly applications aimed at BCC and facilitating health services delivery for underserved populations. To 
other National Health Programs. Other opportunities such as integration with mobile technology and electronic health records are also being explored. To support improved data quality, a call centre is being considered, with a toll free helpline accessible across the country for HMIS users. As the HMIS evolves, both the health managers and the public at large would be able to analyze the available information on the portal for policy interventions.

Data collection and community feedback systems: Community feedback is relevant both for public and private sector service providers, it is particularly important for the public sector service provision since this is largely outside the monitoring influence of the market forces. Evaluation of traditional feedback system such as Citizens Report Card (CRC) an initiative of Public Affairs Centre (PAC) in Bangalore demonstrated the potential of using community feedback for improving public services. Emerging ICTs have a major potential in developing an effective community feedback system. For example, a community feedback initiative named Lokavani project, an e-governance initiative in Sitapur district of Uttar Pradesh was launched in 2004, by the district administration and National Informatics Centre. Lokvani has a Hindi website and includes an online public grievance redressal service. All complaints registered and potential of ICT projects (Table 1)

\begin{tabular}{|c|c|c|c|c|c|c|c|c|}
\hline \multirow[t]{2}{*}{ Media } & \multicolumn{2}{|c|}{ Married women $18-34$ yrs } & \multicolumn{2}{|c|}{ Married men 18-34 yrs } & \multicolumn{2}{|c|}{ Married women $35+$ yrs } & \multicolumn{2}{|c|}{ Married men $35+$ yrs } \\
\hline & Reach & Growth & Reach & Growth & Reach & Growth & Reach & Growth \\
\hline TV viewership (past week) & 23 & 10 & 28 & $(-3)$ & 19 & 23 & 21 & 14 \\
\hline Radio listenership (past week) & 15 & 10 & 30 & $(-9)$ & 15 & 45 & 22 & $(-10)$ \\
\hline Ownership of mobile phone & 2 & 48 & 14 & 50 & 1 & 9 & 8 & 66 \\
\hline
\end{tabular}

\section{Key findings}

The review covered the use of ICT in improving service delivery systems and fostering behavior change among beneficiaries ${ }^{5}$. Applications that aimed at improving service delivery systems were reviewed, including Health Management Information Systems, data collection systems, community feedback systems, ICT-based education and training, telemedicine, and the use of ICT as a decisionsupport system.

Health Management Information Systems (HMIS): The development of an integrated, national web-based reporting system for the Ministry of Health and Family Welfare (MoHFW) commonly referred as the NRHM HMIS has been a significant step in the recent past. This HMIS was launched in October 2008 to facilitate district level data capturing and preparation of analytical reports. In order to make the NRHM HMIS as a single point of reference for all health related information, it is being expanded to include sub-district level penetration, integration with advanced Geographical Information System (GIS) capabilities and integration with through the website reach the office of the District Magistrate, who personally monitors each complaint with support of six officers who are required to update the website once an action has been taken ${ }^{6}$. As part of the project, existing computer training institutes and cyber cafes were designated as Lokvani centers. As of June 2008, 115 Lokvani kiosks are operational in Sitapur district. According to Lokvani project documents, in June 2008 a total of 117,179 complaints were registered through the Lokvani website and 97 percent of them were addressed 7 . The project also reports that among the services provided through the internet kiosks that are part of this initiative, online public grievance redressal service emerged as the most popular.

ICT in education and training: A number of ICTs have been used in education and training such as: a) access devices such as computers and mobile devices (e.g. mobile phones, PDAs), b) networking and communication technologies like the internet, c) storage devices like optical discs, and d) elearning platforms like websites, bulletin boards and videoconferencing. Though there are no successful large scale

\footnotetext{
${ }^{4}$ Based on Indian Readership Survey (IRS), 2007 and 2008; percent reach in 2008 and percent growth is reported annualized growth between $2007-08$.

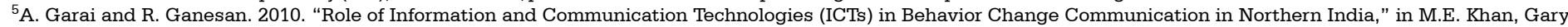

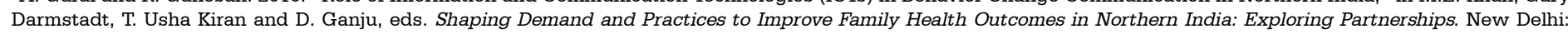
Population Council. (forthcoming)

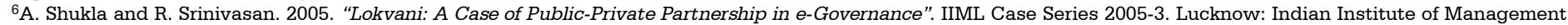
Lucknow. Available at: http://pilibhit.nic.in/lokvani/rojgar/lokvani.pdf.

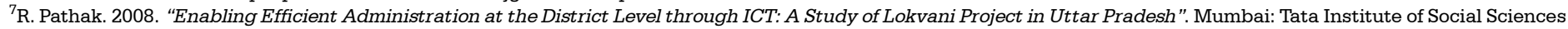
Available at http://sitapur.nic.in/lokvani/allabout/Lokvani_tiss.pdf
} 
projects reported from India, project reviewed from other developing countries shows that it is feasible and hence could be experimented, especially with the frontline health workers in India.

Decision support: Frontline health workers and trained medical practitioners use various job-aids, flow-charts and checklists to adhere to correct protocols, during counseling, diagnosis and treatment provision. ICTs automate job-aids, flow-charts and checklists using algorithms, known as decision support systems (DSS). DSS projects have shown improved counseling, increased adherence to protocols, diagnosis and treatment provision among FHWs and trained medical practitioners.

The above applications were found to have an indirect effect on BCC strategies by providing data to managers for informed decision-making and improving the productivity of frontline health workers, as well as the quality and timeliness of their interaction. Applications aimed at fostering behavior change among beneficiaries, including those using one or more of fixed and mobile telephony (including SMS), the web and games are summarized below.

Two communication modes using ICTs: As highlighted earlier, rural areas are witnessing a rapid growth in mobile phone coverage and usage, both among men and women. Further, the on-going implementation of CSCs will provide rural communities with unprecedented access to the internet. The review identified two types of communication using SMS, telephony and the web or email in terms of how they were designed. Some were designed as a single interaction between the sender (implementer) and receiver (beneficiary) while others were designed to have multiple interactions between the sender and each receiver.

Single interaction systems: Bulk SMS services-where the same message is sent to many recipients enrolled with a provider-is an example of this system. Various web-based yellow pages, customer care services and help lines send such SMS to their subscribers. Project reports reviewed suggest that such a system is effective in increasing awareness on a topic or issue, addressing the specific queries of individuals interested in undertaking an action-usually regarding the location of a service delivery point (referral)-and as a reminder. In this context, in January 2010, the Mangalore Deputy Commissioner announced a scheme through the mobile operator BSNL, by which all its subscribers would be sent an SMS two days prior to the polio immunization day ${ }^{8}$. Other examples are sending referrals to service delivery points (saadhan HIV-AIDS helpline, Dimpa clinics helpline, etc.)

Multiple interaction systems: In this system, beneficiaries enroll to receive on-going messages from a service provider and interact with this system by providing

\footnotetext{
${ }^{8}$ Deccan Herald. 2010. Pulse polio programme

$<$ http://www.deccanherald.com/content/45106/pulse-polio-programme-january10.html>

${ }^{9} \mathrm{~K}$. Patrick et al. 2009. "A Text Message-Based Intervention for Weight Loss: Randomized Controlled Trial," Journal of Medical Internet Research < http://www.jmir.org/2009/1/e1>
}

information pertaining to their health status or behavior, asking questions and getting answers. Messages sent to recipients are customized, based on the input they provide, and the system supports the recipient through the behavior change process. This system has an extensive body of evidence showing its effectiveness in improving health status, behavior modification and increased adherence. A brief illustration of three multiple interaction systems is provided below.

Weight loss program: In this randomized controlled trial, the effectiveness of SMS and multimedia message service (MMS) for weight loss among overweight adults was evaluated $^{9}$. Participants in the intervention group received customized SMS and MMS messages, 2-5 times a day, printed materials and brief monthly phone calls from a health counselor. SMS were generated automatically from a database using pre-determined algorithms and user profiles (Box 1).

Box 1: Customized SMS and MMS messages in the weight loss program

- A topic message on Monday, Wednesday, Thursday, and Saturday such as "Control your portions by setting aside a large snack package into smaller bags or buy 100 calorie snack packs!"

- A question each day asking the participant to reply, such as "How often do you meal plan? A) Every day; D) Every now and then; $G$ ) Never." ( $A, D$, and $G$ were chosen to simplify the use of the key pad for responses since they required only one touch because phones commonly cluster three letters on each button, for example, $A B C, D E F, G H I$.

- Tips or questions on Tuesday, Friday and Sunday that were tailored to the participant's eating behaviors

SMS were related to motivation, guidance for goal setting, assessment of progress against goals set, tips and reminders. SMS also included questions on participants' plans and actions. Responses to these questions were used to customize future SMS. At the end of four months, after controlling for sex and age, the intervention group had lost more weight as compared to the control group.

\section{IFFCO Kisan Sanchar Limited (IKSL): IFFCO is a} cooperative that provides inputs to farmers across India. IFFCO and Airtel jointly launched IKSL in November 2007 to provide information to farmers that would improve their farming activities. Any person intending to use the IKSL mobile telephony service purchases a special subscriber identity module (SIM) card, called Green SIM, that is

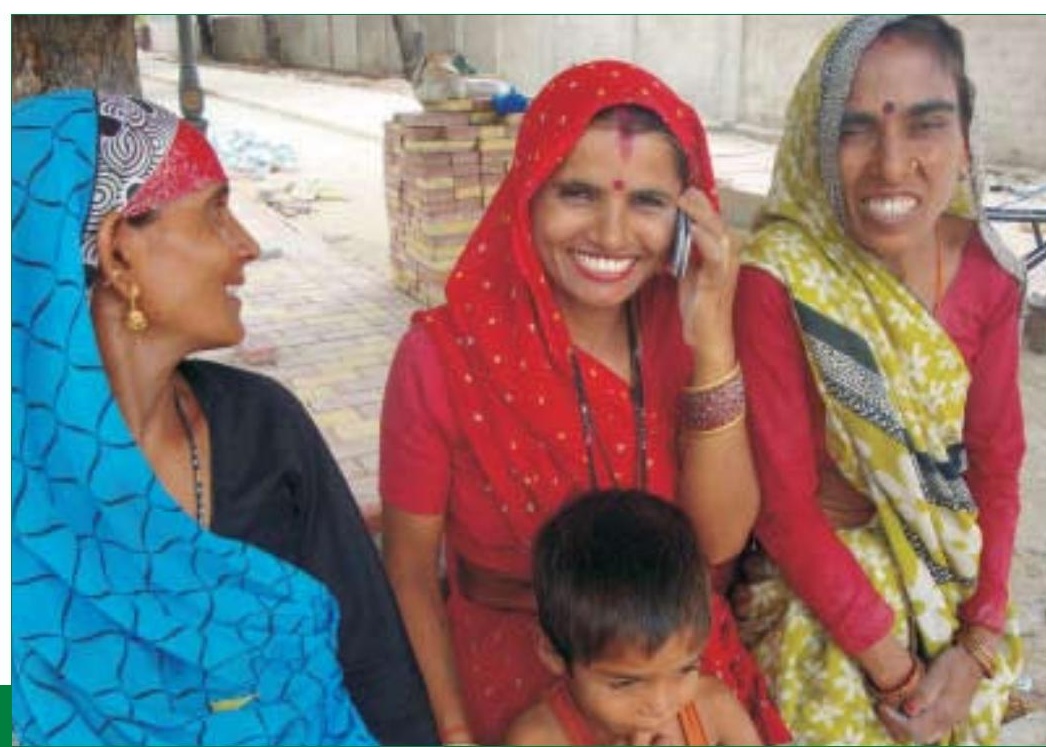


distributed through local mobile connection retailers, cooperative societies, IFFCO outlets and other societies. Following activation of the SIM card, the subscriber receives five prerecorded voice calls on the mobile phone. The calls provide information on the weather, crops and animal husbandry advisories, market prices, fertilizer availability, electricity timings and government schemes. Farmers can call a helpline to ask questions on farming. By October 2009, IKSL was operational in 18 states, addressing 3 million subscribers.

A survey conducted in December 2008 covering 1,167 subscribers in Bihar, Karnataka, Rajasthan and UP found that 91 percent of subscribers were from the rural areas, while others were from semi-urban areas. The subscriber share of the R4 and R5 groups (the lowest socio-economic class) in the rural socio-economic classification grid was 42 percent in Bihar $(\mathrm{N}=314), 29$ percent in Karnataka ( $N=253), 31$ percent in Rajasthan $(\mathrm{N}=271)$ and 16 percent in UP $(\mathrm{N}=329)$.

\section{BabyCenter India: BabyCenter is an} interactive network targeting pregnant and new mothers. It provides personalized, stagebased email and SMS messages (tied to gestation / baby's age) addressing a wide range of topics relevant to pregnant women and new mothers. In India, the website had 3.5 million users in December 2009 and received 2,000 discussion posts a day. The site provides expert-vetted content and parent-to-parent advice. BabyCenter India has launched a phone-based platform, combining daily SMS messages and prerecorded voice content, accessed through an Interactive Voice Response system. Users receive customized emails from pregnancy till the child is 3 years of age. Messages focus on maternal and child health issues such as nutrition, iron folic acid tablets and danger signs during pregnancy. The BabyCenter seeks to adapt this platform in the long term to cover a significant proportion of the Indian market, including rural, low literacy women, poorly trained frontline health workers, and consumers seeking reliable information on health.

\section{Implications for the BCC strategy}

In the near future, as compared to conventional mass media, ICTs, particularly mobile phones, are likely to have as much or wider reach among rural populations in UP. Thus, the review highlights the need to incorporate ICT-based approaches for behavior change to complement approaches adopted in other media.

Single interaction systems using ICT are used in many health projects; however, multiple interaction systems have not yet been adopted in a significant way in health projects in India. Evidence suggests that multiple interaction systems are far more effective than single interaction systems. This study advocates scaling up such multiple interaction systems using ICTs.

Multiple interaction systems have been adopted by the commercial sector in India, as demonstrated by the IKSL and BabyCenter initiatives. IKSL has also demonstrated that it is possible to overcome literacy barriers by using pre-recorded voice calls instead of SMS. The availability of content and service providers with an interest in health and the geographic spread of ICT across the state offers opportunities for developing sustainable models in ICT based communication for beneficiaries.

Suggested citation: Population Council. 2010. Role of information and communication technologies (ICTs) in behavior change communication, Policy Brief No. 12. New Delhi: Population Council.

For additional information, contact: Population Council, Zone 5A, India Habitat Centre, Lodi Road, New Delhi 110003, or email info-india@popcouncil.org, or contact Abt Associates Inc, 201 Second Floor, Aurobindo Place Commercial Complex, Hauz Khas, New Delhi 110016.

\section{(2 Population Council}

Research that makes a difference
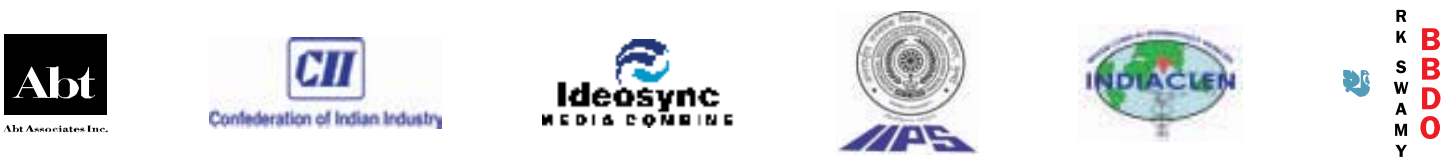

The opinions expressed in this publication do not necessarily reflect the views of the funding agencies. 